Daimon. Revista Internacional de Filosofía, Suplemento 5 (2016), 407-414

ISSN: 1130-0507 (papel) y 1989-4651 (electrónico)

http://dx.doi.org/10.6018/daimon/269241

\title{
El secreto de los cuerpos y el cuerpo del secreto
}

\author{
The secret of the body and the body of the secrets
}

\author{
FRANCISCO JAVIER GALLEGO DUEÑAS*
}

Resumen: La concepción simmeliana del secreto centraba la atención en el enorme poder que tiene para unir a las personas que lo comparten. La sociología del secreto intenta explicar cómo funciona este mecanismo. El cuerpo, a veces, es el objeto a esconder: funciones corporales relacionadas con la comida, el descanso o el sexo que necesitan seguridad y privacidad. La teoría sobre el proceso civilizador de Elias abundaba en esta idea. Por otra parte, el cuerpo puede ser una herramienta efectiva para esconder, compartir o incluso, revelar secretos. El cuerpo se convierte en un significante, el propio cuerpo es un símbolo para los secretos. La manera con la que gestionamos nuestro cuerpo ejemplifica las cualidades del funcionamiento social del secreto. El tema artístico Nuda Veritas resume perfectamente este concepto: el cuerpo desnudo es la metáfora de la verdad desnuda.

Palabras clave: sociología del secreto, proceso civilizador, comunicación, intimidad.

\begin{abstract}
Simmel's conception of secret focus on its great power of unified people who share it. Sociology of secrecy tries to explain how it works. The body sometimes is the object to hide: corporal functions related with feed, rest or sex need safe privacy. Norbert Elias' theory on the civilizing process insisted on this idea. In the other hand, the body can be an effective tool to hide, share or even reveal secrets. Body becomes a signifier; the body itself is a symbol for secrets. The way we managed our body exemplifies the qualities of social working of secrecy. The artistic topic Nuda Veritas can summarize this concept: nude body means naked truth.
\end{abstract}

Keywords: Sociology of secrecy; civilizing process; communication; intimacy.

Los estudios sobre el secreto abarcan muy diversos puntos de vista desde que hace más de una centuria Georg Simmel (1986) publicara su estudio sobre El secreto y la sociedad secreta (1908). Simmel abrió una puerta hacia la comprensión de un fenómeno esquivo por su propia naturaleza y permitió diversos puentes hacia la sociología, la antropología, la filosofía o la linguiística. La gran aportación del sociólogo y filósofo alemán fue consi-

Fecha de recepción: 10/06/2016. Fecha de aceptación: 25/07/2016.

* Grupo de Investigación Comunicación y Ciudadanía Digital UCA. Investigador externo del Grupo Compostela de Estudios sobre Imaginarios Sociales GCEIS. Líneas de investigación: sociología del secreto y sociología folk. Artículos, entre otros: "Cartografías y geografías del secreto: El secreto como espacio-tiempo social" en Intersticios: Revista sociológica de pensamiento crítico. Vol. 9, Núm. 1. Págs. 17-39. (2014): "Sociología folk vs. sociología académica: El caso de "Cómo conocí a vuestra madre" en Aposta: Revista de ciencias sociales, №.60,2014,30 págs. E-mail:mua2001es@yahoo.es 
derar la cualidad de unión que el secreto tiene para aquellos que lo comparten, canonizado en las sociedades secretas, frente a la consideración inicial de un carácter diferenciador, separador que desde su propia etimología el secreto sugiere.

La pista de la comunión del secreto permite aflorar lo que de intimidad compartida (José Luis Pardo, 2004) o de atmósfera constituyente (Sloterdijk, 2003) tiene este fenómeno singular. Más allá de las consideraciones de excepcionalidad que parece sugerir el secreto, realmente es una práctica social habitual y cotidiana. Simmel acertaba cuando comenzaba su análisis resaltando la imposibilidad física y psicológica de saberlo todo de una persona, por lo que nos vamos manejando en la vida diaria conformándonos con zonas de penumbra que no nos impiden el desenvolvimiento vital. No necesitamos saber de los problemas conyugales del tendero mientras no engañe en el género ni en el precio.

También acertaba Simmel en añadir un excurso sobre el adorno dentro del marco del secreto y la ocultación. Lo que nos ocupa ahora es precisamente las relaciones del cuerpo con el secreto como objeto básico de ocultación y como modelo para aprender, gestionar y explicar el funcionamiento social del secreto, en suma, como se in-corpora el secreto.

Quizás fuera Michel Foucault (2006) quien más claramente relacionara el cuerpo con el secreto en la dialéctica del saber/poder. Además de las consideraciones sobre el biopoder y la microfísica de éste, Foucault (1980) nos indica cómo un uso principal del secreto es la confesión. No sólo es comunicable, como ya intuíamos con Simmel, el secreto es básicamente para contarlo (Bellman, 1984).

El término secreto posee básicamente dos acepciones. La primera es la que usamos en expresiones como "el secreto de la vida" o "el secreto de las pequeñas cosas". En este caso equivale a esencia, oculta, pero esencia. Sin embargo, sociológicamente lo podemos definir como una práctica social en la que un actor o actores, en una determinada situación, evitan, limitan o modifican la comunicación de algo (acción, pensamiento, sentimiento...) a otro actor o actores, durante cierto tiempo, haciendo uso de ciertas tácticas, es decir, suponiendo un esfuerzo.

Tras Simmel, se ha abordado el tema del secreto desde diferentes puntos de vista: la política, (Shils, 1956), la literatura (Kermode, 1979), la jurisprudencia (Scheppele, 1988), la criptografía (Fabri, 2001), la historia (Vincent, 1998), la psicoterapia (Imber-Black, 1999), la sociología (Bok, 1982, Giraud, 2006; Petitat, 1998), la psicología (Kelly, 2002, Van Mannen y Levering, 1999), la antropología (Teft, 1980; Zempléni, 1976, 1984). Debemos ser conscientes de que el secreto es una práctica social que consiste, no sólo en ocultar, sino que se desenvuelve entre tres acciones: guardar, compartir y desvelar, lo que da pie a diferentes usos sociales de éste.

De todos los usos sociales del secreto, quizás el defensivo sea el más obvio. El cuerpo, ciertas partes del cuerpo, se convierten en objeto de ocultamiento. Es una decisión en cierto modo arbitraria y caprichosa. Los pectorales masculinos se muestran, los femeninos en ciertas culturas se ocultan. Las piernas han ido ganando visibilidad a lo largo del siglo XX en el mundo occidental. Sin embargo, no es el único uso que el secreto tiene con relación al cuerpo.

En otro lugar definimos el secreto pedagógico (Gallego Dueñas, 2011) como las prácticas en las que el propio secreto ayuda a crecer. No sólo en el sentido de que es un indicio de 
la maduración psicológica que es capaz de discernir que lo que está dentro de la mente está oculto a los demás, también en cuanto, a través del secreto, ofrecemos una imagen ideal, un yo utópico, al que aspiramos a convertirnos.

Compartir ayuda a crear un vínculo íntimo sincero a la par que puede convertirse en moneda de cambio para conseguir apoderarse de secretos ajenos. Cuando se decide ocultar algo, cuando se comparte también, lo ocultado adquiere una relevancia paralelamente a la importancia que damos a la persona con la que lo compartimos. Es un ejemplo de la plusvalía simbólica que lleva aparejada el secreto. No ocultamos lo que consideramos trivial, cotidiano y cuando lo hacemos convertimos lo banal en importante.

Por último, habría que diferenciar entre las situaciones en las que desvelamos nuestro propio secreto de cuando investigamos y divulgamos el ajeno. La situación de confesión, con especial atención al ámbito religioso católico ofrece un modelo que Foucault (2006) utilizó como síntoma para caracterizar toda una sociedad confesante.

Fijemos la atención a las relaciones que el cuerpo tiene con el secreto, que se pueden agrupar en tres líneas:

a) El cuerpo como contenido del secreto

b) El cuerpo como agente

c) El cuerpo como símbolo

\section{a) El cuerpo como contenido del secreto}

Uno de los objetos principales de ocultamiento, pues, es el propio cuerpo, por eso el término obsceno, automáticamente refiere a ciertas partes, con el que podemos tener una intimidad esencial que permite expresiones del tipo partes íntimas, en cierto modo, abuso del lenguaje. Las antiguas partes pudendas son objeto de higiene íntima, no por su carácter interior, sino por su relación con la sexualidad. Quizás, siguiendo la clarificadora decisión de José Luis Pardo (2004), no deberíamos hablar de intimidades, sino de zonas privadas de nuestro cuerpo. Sabemos que existen, sabemos de su uso y disfrute, pero no las compartimos, privamos al público de dichas partes.

El propio hecho de ocultarlas despierta una plusvalía sexual, libidinal (Lyotard, 1990), simbólica (Bourdieu, 1988) porque, como hemos aprendido del secreto, sólo se oculta lo que tiene valor, ergo, todo lo que se oculta ipso facto se carga de valor. La censura, la represión es la que hace aflorar la importancia de un asunto. En inglés (Clark, 2006) se distingue entre el desnudo natural (naked) y el desnudo realizado a propósito, como construcción social (nude). Incluso aparecer con la piel expuesta es fruto del esfuerzo humano. Desvelar es tan artificial, tan práctica social como el ocultamiento. El kilt acostumbra a llevar por encima una especie de saquito peludo que simula los genitales masculinos, que es precisamente la parte del cuerpo que pretende ocultar (Simmel, 1986, Buss, 1996).

El cuerpo como contenido del secreto incluye no sólo las llamadas partes íntimas, también entran dentro de la ocultación las deformidades, la enfermedad, los embarazos, la edad, las pasiones y los afectos. Todos, además, son objetos de rumores, la forma más eficiente de propagar un secreto a través de las redes sociales. 
Las partes del cuerpo también se comparten. Se comparten en la intimidad de las relaciones. Son relaciones íntimas. Esta expresión es quizás el ejemplo más claro de cómo se in-corpora (Lakoff y Johnson, 2001), se hace carne, lo que va más allá de la piel. Amigos íntimos son aquellos que comparten una complicidad extrema, sin que necesariamente haya roce ni desnudo. Enemigos íntimos pueden ser encarnizados batalladores que no toquen pellejo sino armas dialécticas sabiamente dirigidas.

También se comparte el secreto del cuerpo en las consultas de médicos y psiquiatras, en reconocimientos físicos, en confesionarios. Son maneras de desvelar los secretos institucionalizadas. Involuntarias son las ocasiones en las que el propio cuerpo nos traiciona con un gesto, con un sonrojamiento culpable. En palabras de Judith Butller, cuerpos que importan.

Por último, compartimos nuestros secretos a través del arte, de las confesiones por escrito, involuntariamente, que sostendría Freud, a través de lo que dejamos intuir de nuestro subconsciente.

\section{b) El cuerpo como agente}

El cuerpo también muestra el modelo para el manejo del secreto. Se aprenden como tecnologías del yo (Foucault, 1990). El cuerpo sería el continente del secreto. Los gestos participan de su iconografía (Gallego Dueñas, 2013). Para guardar un secreto nada mejor que un dedo índice cerrando unos labios. Para compartirlo, una boca acercándose a un oído y murmurando. Para desvelarlo, un grito. Gran cantidad de posibles técnicas de ocultar, compartir y desvelar un secreto han sido descritas por los trabajos de Erwin Goffman (1993).

Hay técnicas utilizadas para ocultar el cuerpo y sus secretos, pero también, como ya avisaba Simmel, existen técnicas paradójicas que ocultan mostrando. La diferencia entre un jersey ancho y un escote, entre un sombrero y un peluquín. En la teoría topológica del secreto (Gallego Dueñas, 2015a), es una forma exterioridad la que se encarga de ocultar. Alzas, rellenos y fajas, ciertos implantes, pañales, ortopedia y ropa ancha están pensados para que no se noten y aparenten una normalidad. Máscaras, antifaces, corsés, pestañas postizas, maquillaje, lentillas de colores, tintes, rellenos, gafas de sol... tienen como misión hacer más evidente lo que tratamos de ocultar.

Hay modos de vestir que ocultan mientras que otros muestran, y hay que conceder que determinadas vestimentas están ocultas para ser mostradas en ciertas condiciones, llamemos "intimas". La ropa interior puede ser simplemente una prenda cómoda o convertirse en un escaparate lujoso destinado a despertar un deseo en parte ya conseguido. Es lo que también se ha llamado Secreto Posmoderno (Gallego Dueñas, 2015 b), ocultar para mostrar. Si el secreto del que hablaba Baltasar Gracián (2000) consistía en evitarlo, tanto el propio como el ajeno, confesar tanto como oír la confesión, la ideología de la Ilustración perseguía la transparencia como virtud revolucionaria (Benjamin, 1999). En los tiempos inciertos de la posmodernidad la comunicación es el fetiche, la información es la nueva materia prima para crear plusvalías. El método más efectivo para crear esa plusvalía es reducir la oferta por un lado y despertar el deseo para aumentar la demanda por otro. La lingerie cumple esta función, enciende la pasión y la refrena, mantiene la prohibición y la sobrepasa (Bataille, 1988, Baudrillard, 1981). El secreto posmoderno consiste en aceptar la inevitabilidad, incluso la necesidad, del secreto a cambio de que éste sea confesado, compartido, desvelado. Como la propia lencería. 
En cierta forma es comprensible el apartamiento para ciertas funciones biológicas, como las relaciones sexuales, que implican una gran concentración y cierto descuido en percibir los peligros que acechan durante el acto. Sin embargo, el halo de misterio que rodea la sexualidad, como mostró Foucault (1976) es una práctica social construida históricamente.

Los gestos corporales tienden a ocultar, mostrar o compartir selectivamente. Posturas e imposturas, quitarse el anillo de casado, o tomar alcohol para desinhibirse. Todos forman parte de las diversas técnicas del secreto. Dos son las más importantes, el silencio y la mentira. Cercanas a la mentira están la ocultación o el fingimiento, lo que, en suma, Greimas (1976) calificaba del parecer pero no ser. El cuerpo es uno de los artilugios esenciales para llevar a cabo estas estrategias de ocultación de la misma forma que es capaz de autosabotearlas. El nerviosismo, la sobreactuación, la falta de naturalidad motivada por la actuación consciente sobre patrones usualmente inconscientes. Hay que tener un control mucho más férreo sobre las reacciones corporales que sobre el lenguaje. Éste está pensado para mentir, aquel, no tan fácilmente, aunque los fracasos de los detectores de mentiras lo pongan en duda.

\section{c) El cuerpo como símbolo}

Como hemos comprobado, el cuerpo es símbolo del secreto, utilizamos gestos - no sólo gestos- para describir los principales usos que tienen que ver con el secreto (guardar, compartir, desvelar). Lo que practicamos con nuestro cuerpo nos sirve para generalizar el manejo diestro del secreto. El juego del cucu-tras, el escondite son el laboratorio de experimentación para luego generalizar este juego de ocultación y desvelamiento a lo que en nuestro interior pasa. Simmel sostenía que el secreto crea un mundo interior en el niño que descubre con desconfianza que hay partes de él mismo, de su interior, que están fuera del alcance de sus padres. El secreto ayuda a crecer. Crecer como individuo, y si seguimos la disertación de Elias (1987), como civilización.

La obra de Rodin "El secreto" consiste en dos manos que sujetan juntas un objeto. La peculiaridad es que son dos manos derechas. Es difícil expresar más gráficamente la intimidad del secreto compartido.

Eve Kosofsky Sedwick (1990) elaboró una epistemología del armario para desarrollar una teoría de las relaciones del cuerpo con el secreto de la homosexualidad, unas relaciones paradójicas porque nunca se puede salir completamente del armario, siempre existirá una tendencia al hermetismo, más allá de debates esencialistas o constructivistas sobre la homo y heterosexualidad (Buttler, 2005). En la Cabaña de los Hombres de la Melanesia, la masculinidad biológica se basa en la práctica del secreto (Herdt, 2003). Las transformaciones sociales, en especial la llegada de los misioneros ha sido considerada una amenaza para su masculinidad. Por eso deben crear un "yo-masculino" ideal dejando apartadas a las mujeres del rito de la cabaña, la felación ritual.

Por último, la propia misión de la ciencia se basa en descubrir los secretos del universo, en cualquiera de los dos sentidos del término. Y aquí también el cuerpo ofrece un símbolo preciso, la Nuda Veritas, la Verdad Desnuda. En el cuadro de Klimt es una figura femenina desnuda, dirigiendo su atractiva y erótica mirada hacia el espectador, sujetando con su mano derecha un espejo en el que nos presenta la "verdad desnuda" 


\section{Conclusión}

El cuerpo, pues, es en primer lugar, el campo de batalla del secreto. Para desvelarlo tanto como para ocultarlo. La censura y el puritanismo tienen como principal objetivo el hacer obscenas ciertas funciones y partes corporales. Norbert Elias definía, como es sabido, el proceso de civilización como la progresiva ocultación de lo que de animal tiene el humano, relegando fuera del escenario lo relativo a las excreciones, cierta parte de las relaciones e incluso la nutrición se desnaturaliza. Lo que se ha practicado con las funciones corporales, luego se convierte en hipocresía, fingimiento y máscaras.

En segundo lugar, el cuerpo es instrumento para el secreto. Tanto en sus usos de guardar, compartir o desvelar. Es imprescindible hasta el punto de hacerlo significante del concepto.

Por último, el cuerpo es el símbolo del secreto. El manejo del propio cuerpo como contenido oculto/compartido/desvelado nos ejemplifica las cualidades del funcionamiento social del secreto. Es ocultado de manera arbitraria, no importan tanto los contenidos, nos decía Simmel, sino la forma sociológica. Es compartido selectivamente con quienes se tiene una intimidad, a la vez que puede ser el catalizador de esa intimidad. Por último es desvelado como sugería el mandato revolucionario, las vestimentas se acortan, la piel acaba expuesta, pero al fin y al cabo, es necesario cierto secreto para avivar la llama del deseo.

\section{Bibliografía}

Bataille, Georges (1988, 1957): El erotismo. Barcelona. Tusquets.

Baudrillard, Jean (1981): De la seducción. Madrid. Cátedra.

Bellman, Beryl L. (1981): “The Paradox of Secrecy” en Human Studies (4). Págs, 1-24.

Bellman, Beryl L. (1984): The Language of Secrecy. Symbols \& Metaphors in Poro Ritual. New Brunswick. New Jersey. Rutgers University Press.

Benjamin, Walter (1999): Sobre algunos temas en Baudelaire. Disponible en elaleph.com Bok, Sissela (1982): Secrets. New York. Pantheon Books.

Bourdieu, Pierre (1988): La distinción. Madrid. Taurus.

Buss, David M. (1996): La evolución del deseo. Madrid. Alianza.

Buttler, Judith (2005, 1993): Cuerpos que importan: sobre los límites materiales y discursivos del "sexo". Buenos Aires. Paidós.

Clark, Kenneth (2006): El desnudo. Madrid. Alianza.

Di Mascio, Patrick (1994): Le maître de secret. Essai sur l'imaginaire théorique de Freud. L'Or d'Atlante. Champ Vallon.

Elias, Norbert (1987): El proceso de la civilización. México. FCE.

Fabbri, Paolo (2001, 1995): Tácticas de los signos. Barcelona. Gedisa.

Foucault, Michel (1980): Microfísica del poder. Madrid. La Piqueta.

Foucault, Michel (1990): Tecnologías del yo. Barcelona. Paidós/ICE-UAB

Foucault, Michel (2006): Historia de la sexualidad. 1. La voluntad de saber. Madrid. Siglo XXI.

Gallego Dueñas, Francisco Javier (2011): Introducción a una teoría para la (micro) sociología del secreto, Tesis doctoral dirigida por Luis Alfonso Castro Nogueira. UNED. Inédita. 
Gallego Dueñas, Francisco Javier (2013): “Iconografía del secreto" en Intersticios: Revista sociológica de pensamiento crítico. Vol. 7, N. 1, 2013. Págs. 351-374.

Gallego Dueñas, Francisco Javier (2015a): “Cartografías y geografías del secreto: El secreto como espacio-tiempo social" en Intersticios: Revista sociológica de pensamiento crítico. Vol. 9, Núm. 1. Págs. 17-39.

Gallego Dueñas, Francisco Javier (2015b): "El secreto barroco” en Les Cahiers Européens de L'Imaginaire. $\mathrm{N}^{\mathrm{o}}$ 7. Mayo 2015. Págs. 150-151.

Giraud, Claude (2006): Acerca del secreto: contribución a una sociología de la autoridad y del compromiso. Buenos Aires. Biblos.

Goffman, Erving (1993, 1959): La presentación de la persona en la vida cotidiana. Buenos Aires. Amorrurtu.

Gracián, Baltasar (2000, 1647): Oráculo manual y arte de prudencia. Madrid. Siglo XXI.

Greimas, A.J. (1976): Semántica estructural. Madrid. Gredos.

Herdt, Gilbert (2003): Secrecy \& Cultural Reality. Utopian Ideologies of the New Ghinea Men's House. Ann Arbor. University of Michigan.

Imber-Black, Evan (1999): La vida secreta de las familias. Verdad, privacidad y reconciliación en una sociedad del «decirlo todo». Barcelona. Gedisa.

Kelly, Anita E. (2002): The Psychology of Secrets. New York. Kluwer Academic/Plenum Publishers.

Kermode, Frank (1979): The Genesis of Secrecy On the Interpretation of narrative. London. Harvard University Press.

Lakoff, George y Johnson, Mark (2001, 1980): Metáforas de la vida cotidiana. Madrid. Cátedra.

Lochrie, Karma (1999): Covert operations. The Medieval Uses of Secrecy. Philadelphia. University of Pennsylvania Press.

Lyotard, Jean-François (1990, 1974): Economía libidinal. Buenos Aires. FCE.

Muñoz-Millanes, José (1999): “La presencia de Baltasar Gracián en Walter Benjamin”. En Ciberletras ( $\mathrm{n}^{\circ} 1$, agosto, 1999), disponible en http://www.lehman.cuny.edu/ciberletras/ v1n1/ens_08.htm

Pardo, José Luis (2004, 1996): La intimidad. Valencia. Pretextos.

Petitat, André (1998): Secret et formes sociales. Paris. PUF.

Rousseau, Juan Jacobo (1983): Las Confesiones. Madrid. Selecciones Austral.

Scheppele, Kim Lane (1988): Legal Secrets. Chicago. The University of Chicago Press.

Sedgwick, Eve Kosofsky (1990): Epistemology of the Closet. Berkeley-Los Angeles. University of California Press.

Shils, Edward A. (1956): The Torment of Secrecy. London. William Heiman.

Simmel, Georg (1986, 1908): Sociología. Estudio sobre las formas de socialización. Madrid. Alianza. 2 vols.

Sloterdijk, Peter (2003, 1998): Esferas I. Burbujas. Madrid. Siruela.

Sloterdijk, Peter y Heinrichs (2004): El sol y la muerte. Madrid. Siruela.

Tefft, Stanton K. (ed.) (1980): Secrecy. A Cross-Cultural Perspective. New York. Human Sciences Press.

Van Manen Max y Levering, Bas (1999): Los secretos de la infancia. Intimidad, privacidad e identidad. Barcelona. Paidós. 
Vincent, David (1998): The Culture Of Secrecy. Britain, 1832-1998). Oxford. Oxford University Press.

Zempleni, Andras (1976): "La chaîne du secret" en Du secret. En Nouvelle Revue de Psychanalyse (numéro 14, automne 1976). Paris. Gallimard. Pág. 313-324.

Zempleni, Andras (1984): "Secret et sujétion. Pourquoi ses «informateurs» parlent-ils à l'ethnologue?" en Le secret. En Traverses. Revue du Centre de Création Industriele (30-31, mars 84). Centre Georges Pompidou. Págs. 102-115. 